\title{
Chlorophyll a fluorescence and leaf temperature are early indicators of oil palm diseases
}

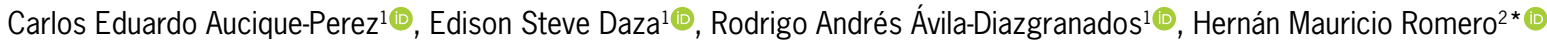

\author{
${ }^{1}$ Corporación Centro de Investigación en Palma de Aceite - \\ Programa de Biología y Mejoramiento de la Palma, Calle 98, \\ 70-91 - Bogotá - Colombia. \\ ¿Universidad Nacional de Colombia - Departamento de \\ Biología, Calle 45, 30-11 - Bogotá - Colombia. \\ *Corresponding author <hmromeroa@unal.edu.co>
}

Edited by: Mark L. Gleason

Received April 16, 2018

Accepted September 04, 2018
ABSTRACT: Bud rot (BR) caused by Phytophthora palmivora and lethal wilt (LW) whose causal agent is unknown, are two diseases currently posing a threat to the oil palm (Elaeis guineensis. Jacq) industry. BR, first reported in 1964, has destroyed more than 85,000 ha. LW, first reported in 1994 in the Llanos Orientales in Colombia, has destroyed more than 5,000 ha. Chlorophyll a fluorescence is useful as a provider of information about the efficiency of the photosynthetic process when plants are subjected to biotic or abiotic stresses. Oil palms affected by BR and LW showed anomalies in the photosynthetic system, manifested by reductions in Fv/F $F_{M}$ and $\Phi P S I I$. Changes in $\Phi P S I l$, variable fluorescence yield $(F v)$ and maximum fluorescence in light-adapted leaves $\left(F_{M}\right)$ were observed from the start of BR infection. The most sensitive and early indicators of LW disease were leaf temperature and basal fluorescence $\left(F_{0}\right) . F v / F_{0}$ significantly changed in diseased palms, indicating problems with movement of electrons through the electron transport chain. Leaf temperature changed in response to both diseases, but variation was greater in LW. We concluded that damage to the photochemical system caused by the diseases affected the processes by which the plant captures and transports energy, causing a physiological imbalance in the plant reflected in the observed variations in chlorophyll a fluorescence and leaf temperature. The two parameters began to change early in the onset of BR and before visual symptoms appeared in LW, which is very important to the management of both diseases, the foundation of which is early detection.

Keywords: Photosystem II, PSII quantum efficiency, Plant-Pathogen Interaction, severity

\section{Introduction}

Oil palm cultivation is under pressure from numerous insect pests and diseases in Latin America. Two of the most significant diseases are bud rot (BR), caused by the oomycete Phytophthora palmivora, (Torres et al., 2010) and lethal wilt (LW) whose causal agent is still unknown although a number of reports have suggested it is a phytoplasma (Alvarez et al., 2014). BR has had devastating effects on plantations in Panama, Costa Rica, Nicaragua, Ecuador, Brazil, Suriname, Peru and Venezuela (Benitez and Garcia, 2015; Sundram and Intan-Nur, 2017; Torres et al., 2010). LW is confined to Colombia but there is a strong possibility of it emerging in other countries (Alvarez et al., 2014).

Bud Rot was first reported in Latin America in Suriname where a plantation was destroyed in 1920, but it is now present in both Central and South America (Sundram and Intan-Nur, 2017; Torres et al., 2016). It has destroyed close to 85,000 ha in Colombia alone, and diseased plants have been found in other countries in large numbers. The losses caused by BR are estimated at USD \$ 250 million with potential to increase, due to the spreading of the disease to other parts of Colombia and other countries in the region. Moreover, it is a constant threat to southeast Asia, because most of the planting materials used in that region are highly susceptible to the disease (Navia et al., 2014)

Lethal wilt was first reported in 1994 in the eastern part of Colombia where more than 5,000 ha have been lost as a result of the disease since that year (Bustillo-Pardey and Arango, 2016). There is a high probability that LW is also present in other countries in the region although it has not yet been formally identified as such. The most important characteristics of these two diseases are summarized in Table 1.

Biotic and abiotic stresses trigger physiological disturbances, which are determining factors in the plant's ability to adapt to specific environmental conditions. Among the responses of plants to stress, chlorophyll a fluorescence is very sensitive to physiological changes in the plant, and it is used for measuring the physiological stage of a plant under both biotic (Chaerle et al., 2004; Ivanov and Bernards, 2016; Rios et al., 2017; Zlatev et al., 2016) and abiotic stresses (Baker and Rosenqvist, 2004; Banks, 2017; Nath et al., 2017).

Leaf temperature also changes with stress. For example, it is affected by the presence of diseases (Berdugo et al., 2014). In general, it is accepted that when pathogens directly or indirectly impair transpiration, the net effect is lack of thermal regulation which results in increases in leaf temperature (Mahlein, 2016). Thus, in several crop diseases, temperature change is used as a diagnostic tool (Berdugo et al., 2014). Therefore, the aim of this research was to develop technologies that allow for early diagnosis of BR and LW. We hypothesized that the onset of BR and LW triggers physiological changes in the palms that can be used for early diagnosis of the diseases. The specific aims of this study were: 1) to monitor chlorophyll a fluorescence in oil palms affected by BR or LW; 2) to measure changes in leaf temperature that could correlate to disease progression, and 3) to establish if changes in the measured physiological parameters could act as early indicators of the disease to facilitate diagnosis. 
Table 1 - Main characteristics of oil palm diseases bud rot and lethal wilt.

\begin{tabular}{|c|c|c|}
\hline & Bud Rot & Lethal Wilt \\
\hline Causal Agent & Phytophthora palmivora & Unknown \\
\hline Disseminators & Unknown & $\begin{array}{l}\text { A vector is involved in infection; a type of sucking insect; the } \\
\text { Haplaxius crudus is suspected }\end{array}$ \\
\hline Symptomatology & $\begin{array}{l}\text { Presence of brown discolorations in the spears, causing mass } \\
\text { destruction of the leaf tissue. At advanced stages, the palm bud is } \\
\text { destroyed }\end{array}$ & $\begin{array}{l}\text { Chlorosis and reddish or coppery coloration of the leaflets, rotting } \\
\text { and drying of inflorescences in their different stages, fruit loses shine } \\
\text { and there is premature fruit drop at all stages of growth }\end{array}$ \\
\hline Epidemiology & Aggregated pattern & Aggregated pattern \\
\hline
\end{tabular}

\section{Materials and Methods}

The study was carried out between 2012 and 2015 in two areas of Colombia where oil palms are grown and which are characterized by high inoculum pressure for each of the diseases studied. The study of BR was carried out in plots in Palmar Santa Elena S.A. located in Tumaco in the department of Nariño in Colombia at a latitude of $\mathrm{N} 1^{\circ} 48^{\prime} 24^{\prime \prime}$ and a longitude of W $78^{\circ} 45^{\prime} 53^{\prime \prime}$. It has an altitude of $32 \mathrm{~m}$ above sea level, an average annual temperature of $28{ }^{\circ} \mathrm{C}$ and an average annual rainfall of 4,000 mm following a mono-modal pattern, with $75 \%$ of rainfall occurring between the months of Mar and Aug.

The Palmar del Oriente plantation was selected for the study of LW. It is located in the municipality of Villanueva in the department of Casanare at latitude $4^{\circ} 36^{\prime} 40^{\prime \prime} \mathrm{N}$ and longitude $73^{\circ} 55^{\prime} 33^{\prime \prime} \mathrm{W}$. The average annual temperature is $27{ }^{\circ} \mathrm{C}$ with a marked dry season between Dec and Mar. The average annual rainfall is $2,500 \mathrm{~mm}$

Bud rot disease was studied in 18-month old dura $\times$ pisifera $(\mathrm{D} \times \mathrm{P})$ oil palms. One hundred plants were planted among palms which were already infected with $\mathrm{BR}$ in a plot with a BR incidence in excess of $90 \%$. After 12 months in the designated site, the level of damage to the $\mathrm{D} \times \mathrm{P}$ plants caused by the disease was assessed using a severity scale for BR (Martínez and Torres, 2007). At least 10 palms of each BR severity grade were chosen for measurement in two independent experiments.

In the case of LW, selection criteria for plants were established in accordance with the LW-specific symptoms shown in Table 2. A plot with the highest inoculum pressure for the disease, with cumulative incidence in excess of $20 \%$, was chosen for monitoring. In this plot, healthy palms in centers of infection (HWC) and infected plants (LW) were selected. A plot without reported LW cases was also selected corresponding to healthy palms outside the centers of infection (HOC). The tests were carried out on the genetic material Papua $\mathrm{D} \times \mathrm{P}$, planted in 1989. The number of palms selected varied between 8 and 10 palms for each severity level. The whole set of measurements was performed in two independent experiments in different plots of the plantation, but the results shown relate to one of the experiments only.

Chlorophyll a fluorescence and leaf temperature were measured using a PAM fluorometer. Ten readings were taken in leaflets of the middle third of leaves 3 and 17 (Forero et al., 2012), and for each palm selected, the measurements of each plant were averaged. The parameters measured were: maximum fluorescence $\left(F_{M}\right)$, basal fluorescence $\left(F_{0}\right)$ and variable fluorescence yield $(F v)$ of dark-adapted leaves (measured at night); steady stage fluorescence $(F s)$, maximum fluorescence $\left(F_{M}{ }^{\prime}\right)$, PSII quantum efficiency (ФPSII) and leaf temperature $\left({ }^{\circ} \mathrm{C}\right)$ in light-adapted leaves (measured during the day). The calculated parameters were Maximum Quantum Yield of PSII Photochemistry $\left(F v / F_{M}\right)$ (Maxwell and Johnson, 2000) and $F v / F_{0^{\prime}}$ (Yordanov et al., 1997); these parameters indicate the stage and efficiency of the electron transport chain (Kalaji et al., 2017b; Yordanov et al., 1997).

The information from both studies was analyzed as a completely randomized design. Treatments were set based on the stage of the symptoms of each disease. The results were analyzed using ANOVA followed by Tukey's test $(p<0.05)$. The statistical SAS package, version 9.0 was used to analyze the information.

\section{Results}

\section{Bud rot}

The measured chlorophyll a fluorescence parameters differed according to severity of disease (Table 3). Thus, in the light-adapted leaves, quantum yield of PSII (ФPSII), and maximum fluorescence $\left(F_{M}{ }^{\prime}\right)$ decreased as the percentage of infected tissue in the palm increased. The reductions in ФPSII were significant given its severity grade 1 (less than $20 \%$ of damage on the spear leaf); however, in the case of $F_{M}{ }^{\prime}$ the differences were statistically significant only when the proportion of infected tissue reached $80 \%$ (Level 5). There was a progressive increase in steady stage fluorescence $(F s)$, which reached a peak at a severity level of 3 and then began to decrease again.

The parameters $F_{0}, F_{M}$ and $F v$, measured in darkadapted leaves at different levels of BR, showed significant differences (Table 3$)$. Basal fluorescence $\left(F_{0}\right)$, defined as the minimum fluorescence generated in darkadapted leaves, showed a notable increase as the plant moved from a healthy stage or the early stages of the disease to the advanced stages of BR. The mean values for the parameters $F_{M}$ and $F v$ began to fall as soon as the first symptoms of the disease were observed (Level 1). In 
the case of $F v / F_{M}$ there was a downward trend with a significant reduction from severity level 3 (stage in which there is $40 \%$ to $60 \%$ damage on the spear leaf).

The stage and efficiency of electron transport, as measured by $F v / F_{0}$, showed significant differences $(p$ $\leq 0.001$ ), decreasing dramatically when the plant was subjected to the harmful effects of BR (Table 3). As in the case of $F v / F_{M^{\prime}}$ the values were significant as soon as the progression of the disease became evident, i.e. when over $40 \%$ of the tissue was infected by BR. The reduction in the flow of electrons from the PSII to the electron transport chain in palms infected by BR was $4 \%, 24 \%$ and $22 \%$ for severity levels 1,3 and 5 , respectively.

Leaf temperature was another parameter which showed significant differences between healthy and BRinfected palms. Figure 1A shows an increase in leaf temperature in palms with tissue damage and over $40 \%$ of infected tissue. Palms with disease severity levels of 3 and 5 showed an increase of $0.9{ }^{\circ} \mathrm{C}$ whereas increases in temperature between healthy palms and palms with severity level 1 were not significant.

\section{Lethal wilt}

The palms affected by LW showed significant changes in chlorophyll a fluorescence (Table 4), an indicator of the damage of the photosynthetic apparatus caused by the disease. In the light adapted leaves the DPSII changed in a similar way as in the plants affected by BR. In this case, ФPSII was lower for palms with LW compared to healthy palms. The same tendency was found in other parameters such as maximum fluorescence $\left(F_{M}{ }^{\prime}\right)$ and steady stage fluorescence $(F s)$; however, there was a difference in the latter parameter between healthy palms outside and within centers of infection, with significantly lower values observed for HWC palms.

In the dark-adapted leaves, the effect of LW was also significant (Table 4). For example, the basal fluorescence $\left(F_{0}\right)$ of the palms with LW was higher than in the healthy palms. HWC showed higher basal fluorescence than HOC, although the differences were not statistically significant.

The parameters $F_{M^{\prime}} F v, F v / F_{M}$ and $F v / F_{0}$ were also affected by the LW in the palms, with significant reductions in the measured parameters in the diseased palms compared to the healthy ones. In certain parameters, such as $F v / F_{0}$, the reduction in effect of the disease was more than $30 \%$ (Table 4).

The differences in leaf temperature between healthy and infected palms were much greater in the palms affected by LW than in those with BR (Figure 1B). The difference in leaf temperature between healthy palms outside centers of infection and infected palms was more than $4{ }^{\circ} \mathrm{C}$. There was also a difference in temperature for some palms within centers of infection:

Table 2 - Phytosanitary characteristics for oil palm material selected for the physiological measurements of damage caused by lethal wilt (LW). Phytosanitary stage

Symptomatological characteristics

Palm infected with lethal wilt (LW)

Chlorosis and drying of lower leaves, copper-colored necrosis of leaflets, rotting of bunches of fruit and inflorescences, fruit loses shine and there is premature fruit fall

Healthy palms outside centers of infection (HOC)

No symptoms related to $L W$ in plots with a high incidence of the disease

Healthy palms within centers of infection (HWC) Palms selected in plots where there have been no cases of LW

Table 3 - Bud rot effects on chlorophyll a fluorescence of oil palm. Steady state fluorescence $(F s)$, maximum fluorescence $\left(F_{M}{ }^{\prime}\right)$ and quantum yield of PSII (ФPSII) were measured on light adapted leaves. Basal fluorescence (Fo), maximum fluorescence, variable fluorescence $\left(F_{M}\right)$ and maximum quantum yield of PSII $\left(F v / F_{M}\right)$ were measured on dark adapted leaves.

\begin{tabular}{|c|c|c|c|c|c|c|c|c|}
\hline Severity Level & $\mathrm{Fs}^{\mathrm{a}}$ & $F_{M}^{\prime a}$ & ФPSII & $\mathrm{FO}^{\mathrm{a}}$ & $F_{M}^{a}$ & $F v^{a}$ & $\mathrm{Fv} / \mathrm{F}_{\mathrm{M}}{ }^{\mathrm{a}}$ & $\mathrm{Fv} / \mathrm{Fo}^{\mathrm{a}}$ \\
\hline HEALTHY & $1.1 \pm 116 \mathrm{c}$ & $1900 \pm 600 a$ & $78 \pm 0.01 c$ & $321 \pm 34 c$ & $1747 \pm 317 a$ & $1426 \pm 298 a$ & $0.81 \pm 0.02 a$ & $4.44 \pm 0.77 a$ \\
\hline Level 1 & $8.7 \pm 1$ & $1801 \pm 681 a$ & $0.77 \pm 0.02 b$ & $313 \pm 49 c$ & $1625 \pm 225 b$ & $1312 \pm 192 b$ & $0.81 \pm 0.02 a$ & $0.69 a$ \\
\hline evel 3 & $9.6 \pm$ & $1830 \pm 613 a$ & $0.63 \pm 0.1 b$ & $402 \pm 118 a$ & $1646 \pm 322 b$ & $1244 \pm 333 b$ & $0.75 \pm 0.09 b$ & $3.39 \pm 1.30 b$ \\
\hline evel 5 & $488.4 \pm 128 b$ & $1185 \pm 614 b$ & $0.48 \pm 0.2 \mathrm{a}$ & $372 \pm 100 b$ & $1601 \pm 433 b$ & $1229 \pm 410 b$ & $0.75 \pm 0.10 b$ & $3.46 \pm 1.28 b$ \\
\hline
\end{tabular}

The information shows the mean \pm SD $(n=10)$. The different letters represent significant differences at the level of severity of BR (Tukey's test $(p<0.05)$.

Table 4 - Lethal wilt effects on chlorophyll a fluorescence of oil palm. Steady state fluorescence $(F s)$, maximum fluorescence $\left(F_{M}{ }^{\prime}\right)$ and quantum yield of PSII ( $\Phi P S I I)$ were measured on light adapted leaves. Basal fluorescence (Fo), maximum fluorescence, variable fluorescence $\left(F_{M}\right)$ and maximum quantum yield of PSII $\left(F v / F_{M}\right)$ were measured on dark adapted leaves. $\mathrm{HOC}=$ Healthy plants outside centers of infection. $\mathrm{HWC}=$ Healthy plants within centers of infection. $L W=$ Plants affected by lethal wilt.

\begin{tabular}{lcccccccc}
\hline Stage & $F s^{a}$ & $F_{M}{ }^{a}$ & $\Phi P S I^{a}$ & $F o^{a}$ & $F_{M}{ }^{a}$ & $F v^{a}$ & $F V / F_{M}{ }^{a}$ & $F V / F O$ \\
\hline HOC & $764.7 \pm 251 \mathrm{a}$ & $2090 \pm 557 \mathrm{a}$ & $0.751 \pm 0.05 \mathrm{a}$ & $339 \pm 38 \mathrm{~b}$ & $2144 \pm 326 \mathrm{a}$ & $1806 \pm 323 \mathrm{a}$ & $0.84 \pm 0.04 \mathrm{a}$ & $5.40 \pm 1.07 \mathrm{a}$ \\
\hline HWC & $553.2 \pm 217 \mathrm{~b}$ & $2251 \pm 618 \mathrm{a}$ & $0.737 \pm 0.07 \mathrm{a}$ & $337 \pm 47 \mathrm{~b}$ & $2042 \pm 312 \mathrm{a}$ & $1705 \pm 294 \mathrm{a}$ & $0.83 \pm 0.03 \mathrm{a}$ & $5.12 \pm 0.90 \mathrm{a}$ \\
\hline LW & $326.1 \pm 87 \mathrm{c}$ & $887.9 \pm 453 \mathrm{~b}$ & $0.511 \pm 0.1 \mathrm{~b}$ & $377 \pm 86 \mathrm{a}$ & $1775 \pm 459 \mathrm{~b}$ & $1398 \pm 428 \mathrm{~b}$ & $0.78 \pm 0.06 \mathrm{~b}$ & $3.82 \pm 1.23 \mathrm{~b}$ \\
\hline
\end{tabular}

aThe information shows the mean $\pm S D(n=10)$. The different letters represent significant differences at the phytosanitary stage (Tukey's test $(p<0.05)$. 



Figure $\mathbf{1}$ - Leaf temperature changes in plants affected by $(A)$ bud rot and (B) lethal wilt. The bars indicate the mean temperature \pm SD. $(n=10)$. BR severity levels are based on the severity scale developed by Martinez and Torres, 2008. Lethal wilt phytosanitary levels correspond to healthy plant outside the center of disease $(\mathrm{HOC})$, healthy plants within the center of the disease (HWC) and plants affected by the disease (LW).

differences of $3{ }^{\circ} \mathrm{C}$ were recorded in some cases. The status of the palms was monitored after the measurements, and it was observed that $40 \%$ of the HWC palms showed visual symptoms of the disease two to three months after the measurements, which might indicate that a number of the palms were already infected, showing the recorded changes in chlorophyll $a$ fluorescence and leaf temperature, corresponding to the onset of the disease, even though external symptoms were not visible.

\section{Discussion}

The analysis of chlorophyll $a$ fluorescence showed that the diseases BR and LW triggered damage at the level of the photosynthetic apparatus of the plant, reducing $F v / F v$ values below 0.83 , which is the value observed for a plant that shows no type of physiological stress (Baker, 2008). The palms which were not under stress had an $F v / F_{M}$ value of 0.8 , whereas palms with $\mathrm{BR}$ had a value of 0.75 at severity levels 3 and 5 and palms with confirmed cases of LW had a value of 0.78. Damage caused by BR and LW affected the physiological processes related to photosynthesis. This response was also observed by Maxwell and Johnson (2000), who noted that different types of stress trigger a noticeable reduction in the $F v / F_{M}$ value, due to a process of photo-inhibition which is brought about by a drop in maximum light absorption efficiency. This light is used in the reduction of quinones
(Q); therefore, the potential to carry out photosynthesis is reduced and the physiological framework of the plant gradually deteriorates. As a result, the plant's defense system, growth and development are significantly affected due to a drop in the supply of assimilates which are necessary to meet demands for the different metabolic processes.

In the case of LW the situation is complex, because when $F v / F_{M}$ is irregular it indicates that the plant shows symptoms of the disease and the only solution is eradication (Rocha et al., 2007); thus, this indicator can only confirm the presence of the disease.

In the case of the quantum efficiency of PSII (ФPSII), it is significantly affected by stress: it decreases continuously as BR and LW progress within the oil palm, indicating that the proportion of energy harnessed by chlorophyll to stimulate the photochemical process is not being used efficiently (Kalaji et al., 2017). In the plants affected by BR, the changes in ФPSII can be measured from the very onset of symptoms (grade 1). This is a key moment for making decisions regarding the introduction of management measures of the disease such as damaged tissue removal and fungicide applications. The recovery of plants infected by BR is at its greatest when intervention takes place at disease severity levels 1 and 2 and the chance of recovery is gradually lost as the disease enters more advanced stages. However, the identification of palms in grade 1 of BR using the severity scale for visual symptoms is not always accurate. Thus the early changes recorded in DPSII could result in a better diagnostics tool for initiating the intervention.

The changes observed in the steady stage fluorescence $(F s)$ for both diseases show that there is an emission of energy via fluorescence (Baker, 2008). The parameters $F_{M}$ and $F_{M}{ }^{\prime}$ ', measured using dark-adapted and light-adapted leaves respectively, showed significant changes, with clear reductions in values between healthy palms and palms infected with BR or LW. This showed that the maximum reduction of quinones was not taking place because reaction centers were not functioning correctly due to the fact that the process of capturing light energy was operationally inefficient (Kalaji et al., 2017a,b).

The drop in $F_{M}$ and $F_{M}{ }^{\prime}$ values observed in palms infected with BR or LW suggests a process of heat dissipation, which was demonstrated by the increase in leaf temperature. For example, palms infected with LW showed higher values for leaf temperature than healthy palms, because of stomatal closing and a decrease in transpiration rates, which produced a physiological drought. In the case of palms infected with $\mathrm{BR}$, up to now there has been no known changes in leaf temperature because of this disease. However, although there was an increase in the leaf temperature caused by both diseases, the extent of this increase was more significant in the case of LW, which could be attributed to the functional collapse of the overall photosynthetic process in 
the diseased palms (Romero et al., 2007), related to the systemic behavior of LW. In the case of BR, leaf temperature variations were lower and more confined to very young leaves, because the disease is localized in the bud of the plant and the effects are local and not systemic.

Increases in the values of $F_{0}$, together with reduction in $F v / \mathrm{F}_{0}$, were observed for both diseases, suggesting a loss of excitation energy, which is required during the transfer of electrons from pigments to reaction centers (Yordanov et al., 1997). Similar observations were made for fatal yellowing disease which affects coconut palms and is caused by phytoplasmas (Maust et al., 2003). Similarly, Ribeiro et al. (2003) observed an increase in basal fluorescence and decrease in $F v / \mathrm{F}_{0}$ when orange trees were infected with Xylella fastidiosa. The increase in $F_{0}$ is caused by an increase in heat stress, which reduces the efficiency of the excitation energy required by the reaction centers of the PSII (Kalaji et al., 2017a; Yordanov et al., 1997). This also happens in oil palms infected with LW: there are less reaction centers available to receive electrons in the photosystem and the overall photosynthetic and assimilation processes are imbalanced leading to the recorded changes in chlorophyll $a$ fluorescence and leaf temperature.

\section{Conclusions}

The measurement of chlorophyll $a$ fluorescence constitutes an effective tool for determining physiological damage caused by BR and LW. Using this method it was possible to establish that these diseases cause considerable damage in the PSII, significantly affecting the process by which light energy is captured and transformed and the flow of electrons through the electron transport chain, which limits the production of energy and reducing power. However, the parameters analyzed for both diseases showed significant differences and the unique characteristics of each disease must be considered. Thus, parameters such as $\Phi$ PSII, $F_{M}$ and $F v$ could be used as early indicators of BR, as they begin to show changes at initial infection stages, whereas for LW leaf temperature and $F_{0}$ are the best early indicators of the onset of the disease. The results show that it is possible to detect these changes in BR diseased plants as early as severity level 1 , whereas in the case of LW the early indicators allow the identification of diseased plants up to three months before the visual symptoms appear.

The results are important to the management of the diseases, which is based on early detection for intervention in the case of BR and for eradication in the case of LW. In the first case, early detection using DPSII, $F_{M}$ and $F v$ improves the chances of recovery of the plants, and lowers the inoculum of $P$. palmivora to reduce the spreading of the disease. In the case of LW early detection using leaf temperature or $F_{0}$ allows for the prompt eradication of palms without visual symptoms of the disease, reducing the chances of disease dissemination.

\section{Acknowledgments}

To the technical and administrative staff at the plantations Palmar Santa Elena S.A. and Palmar del Oriente for their technical and logistical support. This study was supported by the Ministerio de Agricultura y Desarrollo Rural (MADR) (grants 2007R4542-241 and 2007R4543-222) and the Fondo de Fomento Palmero (FFP) administered by Fedepalma.

\section{Authors' Contributions}

Conceptualization: Romero, H.M. Data acquisition: Aucique-Perez, C.E.; Daza, E.S.; Ávila-Diazgranados, R.A.; Romero, H.M. Data analysis: Aucique-Perez, C.E.; Romero, H.M. Design of methodology: Romero, H.M. Writing and editing: Aucique-Perez, C.E.; Romero, H.M.

\section{References}

Alvarez, E.; Mejía, J.F.; Contaldo, N.; Paltrinieri, S.; Duduk, B.; Bertaccini, A. 2014. 'Candidatus Phytoplasma asteris' strains associated with oil palm lethal wilt in Colombia. Plant Disease 98: 311-318.

Baker, N.R. 2008. Chlorophyll fluorescence: a probe of photosynthesis in vivo. Annual Review of Plant Biology 59: 89-113.

Baker, N.R.; Rosenqvist, E. 2004. Applications of chlorophyll fluorescence can improve crop production strategies: an examination of future possibilities. Journal of Experimental Botany 55: 1607-1621.

Banks, J.M. 2017. Continuous excitation chlorophyll fluorescence parameters: a review for practitioners. Tree Physiology 37: 1128-1136.

Benitez, E.; Garcia, C. 2015. The history of research on oil palm bud rot (Elaeis Guineensis Jacq.) in Colombia. Agronomia Colombiana 32: 390-398.

Berdugo, C.; Zito, R.; Paulus, S.; Mahlein, A.K. 2014. Fusion of sensor data for the detection and differentiation of plant diseases in cucumber. Plant Pathology 63: 1344-1356.

Bustillo-Pardey, A.E.; Arango, C.M. 2016. The best practices to stop Lethal Wilt (LW) in oil palm plantations in Colombia = Las mejores prácticas para detener el avance de la marchitez letal (Ml) en plantaciones de palma de aceite en Colombia. Revista Palmas 37: 75-90 (in Spanish).

Chaerle, L.; Hagenbeek, D.; De Bruyne, E.; Valcke, R.; Van Der Straeten, D. 2004. Thermal and chlorophyll-fluorescence imaging distinguish Plant-Pathogen Interactions at an early stage. Plant and Cell Physiology 45: 887-896.

Forero, D.; Hormaza, P.; Romero, H. 2012. Phenological growth stages of African oil palm (Elaeis Guineensis). Annals of Applied Biology 160: 56-65.

Ivanov, D.A.; Bernards, M.A. 2016. Chlorophyll fluorescence imaging as a tool to monitor the progress of a root pathogen in a perennial plant. Planta 243: 263-279

Kalaji, H.M.; Schansker, G.; Brestic, M.; Bussotti, F.; Calatayud, A.; Ferroni, L.; Goltsev, V.; Guidi, L.; Jajoo, A.; Li, P. 2017a. Frequently asked questions about chlorophyll fluorescence, the sequel. Photosynthesis Research 132: 13-66. 
Kalaji, M.H.; Goltsev, V.N.; Zivcak, M.; Brestic, M. $2017 \mathrm{~b}$. Chlorophyll Fluorescence: Understanding Crop Performance; Basics and Applications. CRC Press, Boca Raton, FL, USA.

Mahlein, A. 2016. Present and future trends in plant disease detection. Plant Disease 100: 1-11.

Martínez, G.; Torres, G.A. 2007. Presence of oil palm bud rot in nursery plants $=$ Presencia de la pudrición de cogollo de la palma de aceite $(\mathrm{PC})$ en plantas de vivero. Revista Palmas 28: 13-20 (in Spanish).

Maust, B.; Espadas, F.; Talavera, C.; Aguilar, M.; Santamaría, J.; Oropeza, C. 2003. Changes in carbohydrate metabolism in coconut palms infected with the lethal yellowing phytoplasma. Phytopathology 93: 976-981.

Maxwell, K.; Johnson, G.N. 2000. Chlorophyll fluorescence: a practical guide. Journal of Experimental Botany 51: 659-668.

Nath, K.; O'Donnell, J.P.; Lu, Y. 2017. Chlorophyll fluorescence for high-throughput screening of plants during abiotic stress, aging, and genetic perturbation. p. 261-273. In: Hou, H.J.M.; Najafpour, M.M.; Moore, G.F.; Allakhverdiev, S.I., eds. Photosynthesis: structures, mechanisms, and applications. Springer, Berlin, Germany.

Navia, E.A.; Restrepo, E.F.; Romero, H.M. 2014. Response of six sources of oil palm planting materials from Malaysia planted in the eastern plains of Colombia to bud rot. Journal of Oil Palm Research 26: 73-83.

Ribeiro, R.V.; Machado, E.C.; Oliveira, R.F.; Pimentel, C. 2003. High temperature effects on the response of photosynthesis to light in sweet orange plants infected with Xylella fastidiosa. Brazilian Journal of Plant Physiology 15: 89-97.

Rios, J.; Aucique-Pérez, C.; Debona, D.; Cruz Neto, L.; Rios, V.; Rodrigues, F. 2017. Changes in leaf gas exchange, chlorophyll a fluorescence and antioxidant metabolism within wheat leaves infected by bipolaris sorokiniana. Annals of Applied Biology 170: $189-203$
Rocha, S.; Pedro, J.; Gutiérrez, D.F.; Mosquera, M.; Tovar, M.; Juan, P. 2007. Lethal Wilt in Oil Palm = Marchitez Letal en Palma de Aceite. Centro de Investigación en Palma de Aceite, Bogotá, Colombia (in Spanish).

Romero, H.M.; Ayala, I.M.; Ruíz, R. 2007. Oil palm ecophysiology. Revista Palmas 28: 176-184 (in Spanish, with abstract in English).

Sundram, S.; Intan-Nur, A.M.A. 2017. South American bud rot: a biosecurity threat to southeast Asian oil palm. Crop Protection 101: 58-67.

Torres, G.; Sarria, G.; Martinez, G.; Varon, F.; Drenth, A.; Guest, D. 2016. Bud rot caused by Phytophthora Palmivora: a destructive emerging disease of oil palm. Phytopathology 106: 320-329.

Torres, G.; Sarria, G.; Varon, F.; Coffey, M.; Elliott, M.; Martinez, G. 2010. First report of bud rot caused by Phytophthora palmivora on african oil palm in Colombia. Plant Disease 94: 1163-1163.

Yordanov, I.; Tsonev, T.; Goltsev, V.; Kruleva, L.; Velikova, V. 1997. Interactive effect of water deficit and high temperature on photosynthesis of sunflower and maize plants. 1. Changes in parameters of chlorophyll fluorescence induction kinetics and fluorescence quenching. Photosynthetica 33: 391-402.

Zlatev, Z.; Petrova, Z.; Penchev, E. 2016. Changes in the chlorophyll fluorescence of common winter wheat depending on the weed infestation and the date of application of a set of herbicides. Agrarni Nauki 8: 75-83. 